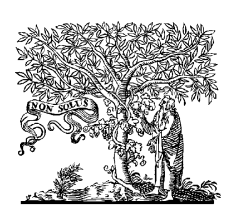

ELSEVIER
PRIMARY CARE

RESPIRATORY

JOURNAL

\title{
EDITORIAL
}

\section{Are six seconds long enough?}

"It's easier and better" sounds like advertising hype, but in the case of six-second spirometry manoeuvres in the primary care setting, it's probably true. All one needs is a spirometer which allows selection of the correct reference values for the forced expiratory volume in one, and six, seconds (FEV1 and FEV6, respectively), and therefore the FEV1/FEV6 ratio [1]. Six-second forced vital capacity (FVC) values were first recommended in 2000 for chronic obstructive pulmonary disease (COPD) case-finding in primary care [2]. The paper by Melbye et al. in this issue [3] provides additional evidence that the FEV1/FEV6 ratio is a good substitute for the traditional FEV1/FVC val(te) for letecting airway obstruction Usually cue to asthmator COPD.

Healthy children can forcefull, exhale almost all of their FVC in less than three seconds. Healthy adults can do so in less than six seconds. However, children with poorly controlled asthma, and adults with COPD, often can continue to exhale for more than 15 seconds if pushed hard during spirometry testing. But for what purpose? To achieve a flat volume-time plateau, indicating an acceptable end-of-test value? Several studies from different countries, using different models of spirometers, and testing patients of all ages, confirm that for detecting airway obstruction, and for ruling out restriction of lung volumes, six-second FVC manoeuvres (when compared to appropriate reference equations) produce the same acceptable misclassification rates as traditional techniques [4-8]. This is good news, because it makes spirometry testing faster and easier for both the patient and the technologist or nurse.
The vast majority of spirometry tests performed in the primary care setting are for one of three indications: firstly, to detect airway obstruction in patients with respiratory symptoms $[9,10]$; secondly, to grade the severity of impairment in patients known to have asthma or COPD; and thirdly, to determine the efficacy of medications prescribed for asthma or COPD. Six-second manoeuvres only help with the first indication, since the FEV1 - which can be measured from manoeuvres - vilich crily last for one second irri, Bes to grade severity and to deferifine therapeutic response from time to time.

Descite the wicespread promotion of the GOLD criteria for detecting COPD in smokers [10] an FEV1/FVC ratio $<0.70$, (or its equivalent, an FEV1/FEV6 ratio $<0.73$ ) - these fixed ratio values should not be used because they cause high misclassification rates $[11,12]$. The fixed ratios are also unnecessary, because all office spirometers automatically calculate the appropriate lower limit of the normal range for the FEV1/FVC value, which declines with age, as shown in Figure 4 of the Melbye et al. paper [3]. The threshold for an abnormal FEV1/FEV6 value ranges from about 0.74 in patients in their early sixties to about 0.64 for patients in their eighties. Despite decades of use, there is no evidence that tests of "small airways disease", such as the FEF $25-75 \%$ or the new sixsecond FEF25-75\% [13], provide better sensitivity or specificity than the FEV1/FVC or FEV1/FEV6 for the early detection of COPD or confirmation of asthma.

Physicians should work with all of their smoking patients to help them to quit, regardless of their spirometry results. Bupropion or varenicline for a 
few months will provide those patients with the best chance of success [14]. Before inhalers are considered for current or former adult smokers with respiratory symptoms who are at increased risk for COPD, spirometry should be done to confirm severe airway obstruction. A minority of patients with severe COPD (FEV $1<50 \%$ predicted) will benefit from a long-acting bronchodilator or inhaled corticosteroids, but there is no evidence that those with mild to moderate COPD (FEV1 > 50\% predicted) derive any benefit from the chronic use of expensive inhalers [15]. Patients with severe airway obstruction have a prolonged forced expiratory time (FET) greater than six seconds, which you can detect using a stethoscope and the second-hand on your wrist watch [16]. You can then confirm the severe airway obstruction (and be reimbursed for it) by performing spirometry. On the other hand, for a non-smoking patient with a history of asthma-like symptoms who is asymptomatic on the day of the office visit, a normal spirometry test does not rule out asthma.

Accurate hand-held spirometers which measure the FEV1/FEV6 ratio and use the appropriate lower limit of the normal range to detect airway obstruction have been commercially available for several years [17]. The National Lung Health Education Program (NLHEP) provides an onlifie checklist of essential features for suchafice spirometers [18]. Inexperlsive, seif-Dadeu' software for training officl staf: to perform snirbmlaty has recent!y become available [19]. Training and continual reviews of spilometry quality are necessary because poorly-performed spirometry risks high misclassification rates $[20,21]$. I propose that three-minute instructional videos for patients who are about to perform spirometry would further improve the speed and quality of spirometry testing. These could be viewed on portable DVD players or MP4 players, which are now smaller (and safer) than a pack of cigarettes.

\section{References}

[1] Hankinson JL, Odencrantz JR, Fedan KB. Spirometric reference values from a sample of the general U.S. population. Am J Respir Crit Care Med 1999;159: 179-87.

[2] Ferguson GT, Enright PL, Buist AS, Higgins MW. Office spirometry for lung health assessment in adults: a consensus statement from the National Lung Health Education Program. Respir Care 2000;45:513-30.

[3] Melbye H, Madbø A, Crockett A. The FEV1/FEV6 is a good substitute for the FEV1/FVC ratio among the elderly. Primary Care Respir J 2006; 15(5):294-8.
[4] Swanney MP, Jensen RL, Crichton DA, Beckert LE, Cardno LA, Crapo RO. FEV6 is an acceptable surrogate for FVC in the spirometric diagnosis of airway obstruction and restriction. Am J Respir Crit Care Med 2000;162:917-20.

[5] Enright PL, Connett JE, Bailey WC. FEV1/FEV6 predicts lung function decline in adult smokers. Respir Med 2002;96:444-9.

[6] Vandevoorde J, Verbanck S, Schuermans D, Kartounian J, Vincken W. FEV1/FEV6 and FEV6 as an alternative for FEV1/FVC and FVC in the spirometric detection of airway obstruction and restriction. Chest 2005;127:1560-4.

[7] Akpinar-Elci M, Fedan KB, Enright PL. FEV6 as a surrogate for FVC in detecting airways obstruction and restriction in the workplace. Eur Respir J 2006;27:374-7.

[8] Swanney MP, Beckert LE, Framptom CM, Wallace LA, Jensen RL, Crapo RO. Validity of the American Thoracic Society and other spirometric algorithms using FVC and FEV6 for predicting a reduced total lung capacity. Chest 2004;126:1861-6.

[9] Enright PL, Studnicka M, Zielinski J. Spirometry to detect and manage COPD and asthma in the primary care setting. Eur Respir Mon 2005;31:1-14.

[10] Pauwels RA, Buist AS, Calverley PM, Jenkins CR, Hurd SS. GOLD Scientific Committee. Global strategy for the diagnosis, management, and prevention of chronic obstructive pulmonary disease. NHLBI/WHO Global Initiative for Chronic Obstructive Lung Disease (GOLD) Workshop summary. Am J Respir Crit Care Med 2001;163(5):1256-76.

[11] Hardie JA, Buist AS, Vollmer WM, Filng!ell I. Bakke PS, Morkve 0 . Risk of over diagnsis of CDFJ in asymptomatic elderlv never-rincters iu Respir J 2002;20:1117-22.

[12] Quaner $\mathrm{DH}$ for the Falling Ratio Working Group, What is the FV ranoe? v N v s si expart.Com/download. Accessed June 20, (0)

[13] hankinson JL, Crapo RO, Jensen RL. Spirometric reference values for the 6 second FVC maneuver. Chest 2003;124: 1805-11.

[14] Henningfield JE, Fant RV, Buchhalter AR, Stitzer ML. Pharmacotherapy for nicotine dependence. CA Cancer J Clin 2005;55:281-99.

[15] AHRQ. Minnesota Evidence-based Practice Center of the Agency for Healthcare Research and Quality. Use of Spirometry for Case Finding, Diagnosis, and Management of Chronic Obstructive Pulmonary Disease (COPD) Publication No. 05-E017-2, August 2005. http://www. ahrq.gov/clinic/tp/spirotp.htm Accessed January 5, 2006.

[16] Kern DG, Patel SR. Auscultated forced expiratory time as a clinical and epidemiologic test of airway obstruction. Chest 1991;100(3):636-9.

[17] Mortimer KM, Fallot A, Balmes JR, Tager IB. Evaluating the use of a portable spirometer in a study of pediatric asthma. Chest 2003;123:1899-907.

[18] National Lung Health Education Program. The NLHEP Spirometer Review Process. http://www.nlhep.org/ resources-medical.html\#review Accessed June 20, 2006.

[19] Stout JW. Spirometry Fundamentals: A basic guide to lung function testing. http://depts.washington.edu/ ventures/UW_Technology/Express_Licenses/spiroFun.php Accessed June 20, 2006.

[20] Eaton T, Withy S, Garrett JE, et al. Spirometry in primary care practice: the importance of quality assurance and the impact of spirometry workshops. Chest 1999;116: 416-23.

[21] Kaminsky DA, Marcy TW, Bachand M, Irvin CG. Knowledge and use of office spirometry for the detection of chronic 
obstructive pulmonary disease by primary care physicians. Respir Care 2005;50(12):1639-48.

Paul L. Enright*

Research Professor of Medicine,

The University of Arizona, 4460 East Ina Road, Tucson, AZ 85718, USA

Available online at www.sciencedirect.com $\because$ ScienceDirect

Available online at http://www.thepcrj.com

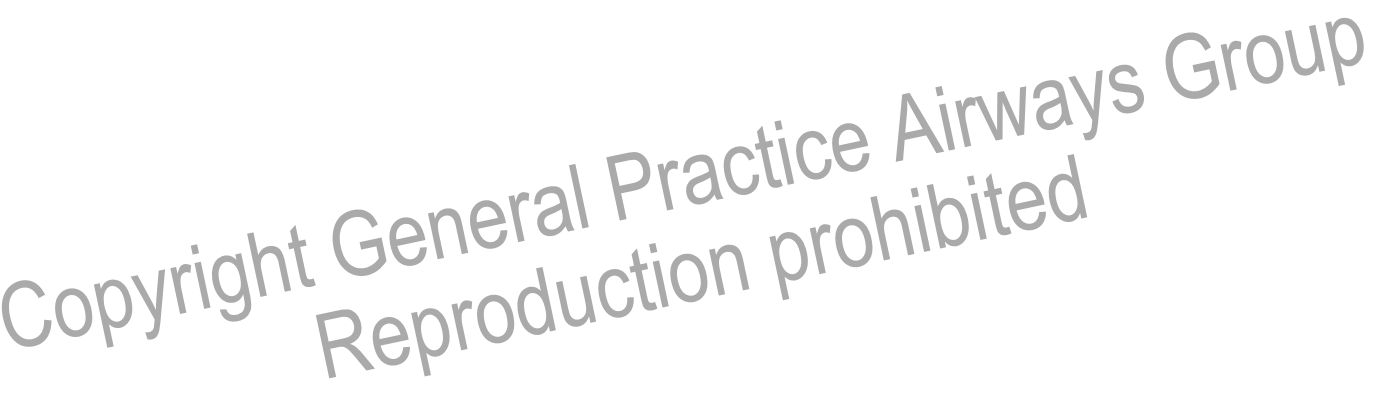

